\title{
Association of Sedentary Time and Physical Activity with the 10-Year Risk of Cardiovascular Disease: Korea National Health and Nutrition Examination Survey 2014-2017
}

\author{
Yena Lee, Joung Sik Son*, Yoon Hee Eum, Ok Lim Kang \\ Department of Family Medicine, Seoul National University Hospital, Seoul, Korea
}

\begin{abstract}
Background: Sedentary behavior is associated with increased cardiovascular disease (CVD) risk. We investigated this association of sedentary time and physical activity with increased 10-year CVD risk in Korean adults.

Methods: This cross-sectional study used data from the Korea National Health and Nutrition Examination Survey (2014-2017). In total, 14,551 participants aged 30-74 years (6,323 men, 8,228 women) were analyzed. The usual length of sedentary time per day was categorized into three groups $(<6,6-<9$, or $\geq 9 \mathrm{~h} / \mathrm{d}$ ), and physical activity (metabolic equivalents [METs].min/wk) was categorized into two groups (low, $<600 \mathrm{METs} \cdot \mathrm{min} /$ wk; moderate/high, $\geq 600 \mathrm{METs} \cdot \mathrm{min} / \mathrm{wk}$ ). Logistic regression analysis was performed to assess the association between sedentary time and increased CVD risk (predicted 10-year risk $\geq 10 \%$ ). Adjusted variables were age, sex, body mass index, marital status, employment, household income, alcohol use, family history of CVD, and comorbidity (hypertension, diabetes, and dyslipidemia).

Results: The average sedentary time for the 14,551 participants was $7.49 \mathrm{~h} / \mathrm{d}$, with an average 10-year CVD risk of 9.58\%. There was no significant association between sedentary time and increased 10 -year CVD risk in the moderate/high physical activity group. In the low physical activity group, sedentary time $\geq 9 \mathrm{~h} / \mathrm{d}$ had a significant association with increased CVD risk (odds ratio [OR], 1.29; 95\% confidence interval [CI], 1.04-1.62). However, when the sedentary time was $<6 \mathrm{~h} / \mathrm{d}$, no significant associations were found (OR, 1.17; 95\% CI, 0.92-1.49).

Conclusion: In the low physical activity group, reduction of sedentary time might be important for preventing increased CVD risk.
\end{abstract}

Keywords: Sedentary Behavior; Exercise; Cardiovascular Diseases

Received: July 17, 2019, Revised: September 23, 2019, Accepted: October 1, 2019

*Corresponding Author: Joung Sik Son https://orcid.org/0000-0003-2460-3378

Tel: +82-2-2072-0175, Fax: +82-2-766-3276, E-mail: medical114@naver.com 


\section{INTRODUCTION}

One in four people worldwide is not sufficiently physically active. ${ }^{1)}$ The World Health Organization (WHO) identifies insufficient physical activity as a major risk factor for death globally and a key risk factor for noncommunicable diseases such as cancer, diabetes mellitus, and cardiovascular disease (CVD). Physical activity contributes toward health improvement and prevention of noncommunicable diseases, ${ }^{1)}$ whereas sedentary behavior is related to deleterious health outcomes such as all-cause mortality, CVD mortality and incidence, and cancer mortality and incidence. ${ }^{2)}$ Sedentary behavior is commonly defined as "any waking behavior characterized by an energy expenditure $\leq 1.5$ metabolic equivalents (METs) while in a sitting or reclining posture."3)

According to statistics released by Statistics Korea in 2017, heart and cerebrovascular diseases are the second and the third most common cause of deaths, respectively. ${ }^{4)}$ Several studies have been conducted to predict the incidence of CVD as it is a major cause of death not only in Korea but also worldwide.

Several studies have investigated the association between sedentary behavior and CVD. Until recently, the association between sedentary time and CVD has been a controversial issue. Increasing evidence has shown that prolonged sedentary time is independently associated with CVD-related mortality and incidence, regardless of physical activity. ${ }^{2,5-9)}$

In this study, we examined associations between sedentary time and 10-year CVD risk in different physical activity groups and aimed to determine the importance of sedentary time, with the assumption that it is an important factor for increased 10-year CVD risk within the same physical activity group and even among different groups according to physical activity level.

\section{METHODS}

\section{Participants}

In this cross-sectional study, data were obtained from the Korea National Health and Nutrition Examination Survey between 2014 and 2017 (KNHANES VI-VII). The KNHANES is a nationwide, populationbased survey in the Republic of Korea that was designed to collect information on the nutritional and health status, sociodemographic status, and health behaviors of Koreans. Data from health interviews and examination surveys of KNHANES were used for the analysis.

Among the 31,207 individuals who participated in KNHANES between 2014 and 2017, we included participants aged 30-74 years in this study because the Framingham risk score could be used to predict CVD risk at these ages. ${ }^{10)}$ We excluded patients who were diagnosed with any cancer $(n=899)$, stroke, angina, or myocardial infarction $(n=712)$. Pregnant women $(n=106)$ and those who had no information on sitting time $(n=2,375)$ or physical activity $(n=2)$ were also excluded. Data from 14,551 participants were available for this analysis. The study protocol was approved by the Seoul National University Hospital Institutional Review Board (approval no., E-1908-068-1054), and the need for informed consent was waived, as the subjects'records and in- formations were anonymized and de-identified prior to analysis.

\section{Measurements}

\section{1) Sedentary time and physical activity}

Sedentary time and physical activity were defined and evaluated using the Global Physical Activity Questionnaire (GPAQ), ${ }^{11,12)}$ proposed by the WHO as a self-written health questionnaire. The GPAQ consists of 16 questions on occupational physical activity, leisure-time physical activity, commuting physical activity, and sedentary behavior. The reliability and validity of its Korean version have been verified. ${ }^{13)}$

The following questions were used to assess the sedentary time: "Except for sleeping time, how much time do you usually spend sitting or reclining on a typical day?" Previous studies have reported that a sedentary time of $>8$ and 10 hours was associated with CVD risk. ${ }^{14,15)}$

Based on the fact that the average sedentary time of all participants in this study was 7.49 hours, we set 6 and 9 hours, which are about 1.5 hours apart from 7.49 hours, as the basis for the classification of sedentary time. The total sedentary time in hours per day $(\mathrm{h} / \mathrm{d})$ was used as a categorical variable and divided into three categories $(<6,6-<9$, and $\geq 9 \mathrm{~h} / \mathrm{d}$ ).

To define physical activity, we used the GPAQ questionnaire on occupational and leisure-time physical activity. In the questions, "vigorous-intensity activities" are activities that require hard physical effort and cause large increases in breathing or heart rate, whereas "moderate-intensity activities" are those that require moderate physical effort and cause small increases in breathing or heart rate. In this study, commuting physical activity in the GPAQ questionnaire was not used. Instead, the questions "How many days have you walked at least 10 minutes at a time in the last week?" and "How many hours do you usually walk per day?" were used for further assessment of walking as a physical activity. ${ }^{16)}$

METs are commonly used to express the intensity of physical activities. One MET is defined as the amount of oxygen consumed while sitting at rest and is equal to $3.5 \mathrm{~mL} \mathrm{O}$ per $1 \mathrm{~kg}$ body weight.min. Moreover, it is equivalent to a caloric consumption of $1 \mathrm{kcal} / \mathrm{kg} / \mathrm{h}$. The total physical activity is expressed as METs.min/wk and categorized into three groups according to the total physical activity level based on the GPAQ analysis guideline (low, moderate, or high). ${ }^{17)}$ We applied 8.0 METs to vigorous-intensity activities, 4.0 METs to moderate-intensity activities, ${ }^{17)}$ and 3.3 METs to walking. ${ }^{16)}$ Thereafter, we classified the activity groups based on the WHO-recommended minimum level of 600 METs-min/wk. ${ }^{18)}$ The "low" activity group was the group with the lowest total physical activity (<600 METs·min/wk), the "moderate" activity group achieved at least $600 \mathrm{METs} \cdot \mathrm{min} / \mathrm{wk}$ but $<3,000 \mathrm{METs} \cdot \mathrm{min} / \mathrm{wk}$, and the "high" activity group achieved at least 3,000 METs.min/wk. ${ }^{17)}$ We integrated the moderate and high activity groups for the analysis.

Further, six sedentary lifestyle groups were created using the sedentary time and physical activity as combined variables, in which the lowest sedentary time $(<6 \mathrm{~h} / \mathrm{d})$ and moderate/high physical activity ( $\geq 600 \mathrm{METs} \cdot \mathrm{min} / \mathrm{wk}$ ) served as the reference category (group 1). 
2) Estimation of the 10-year CVD risk based on the Framingham Heart Study

The "Framingham Heart Study 10-year CVD risk calculator" was used to calculate the 10-year CVD risk prediction value using the following parameters: sex (categorical, male or female), age (continuous, years), systolic blood pressure (continuous, $\mathrm{mm} \mathrm{Hg}$ ), high-density lipoprotein

Table 1. Sociodemographic characteristics of study participants according to sedentary lifestyle groups

\begin{tabular}{|c|c|c|c|c|c|c|c|c|}
\hline \multirow[b]{2}{*}{ Characteristic } & \multirow[b]{2}{*}{$\begin{array}{c}\text { Total } \\
(\mathrm{N}=14,551)\end{array}$} & \multicolumn{3}{|c|}{ Moderate/high physical activity $(n=8,053)$} & \multicolumn{3}{|c|}{ Low physical activity $(n=6,498)$} & \multirow[b]{2}{*}{ P-value } \\
\hline & & $\begin{array}{c}\text { Group 1: } \\
\text { sedentary time } \\
<6 \mathrm{~h}\end{array}$ & $\begin{array}{c}\text { Group 2: } \\
\text { sedentary time } \\
6-<9 \mathrm{~h}\end{array}$ & $\begin{array}{c}\text { Group 3: } \\
\text { sedentary time } \\
\geq 9 \mathrm{~h}\end{array}$ & $\begin{array}{c}\text { Group 4: } \\
\text { sedentary time } \\
<6 \mathrm{~h}\end{array}$ & $\begin{array}{c}\text { Group 5: } \\
\text { sedentary time } \\
6-<9 \mathrm{~h}\end{array}$ & $\begin{array}{c}\text { Group 6: } \\
\text { sedentary time } \\
\geq 9 \mathrm{~h}\end{array}$ & \\
\hline Total & & 2,964 & 2,332 & 2,757 & 2,156 & 1,762 & 2,580 & \\
\hline Age $(y)$ & $51.10 \pm 12.14$ & $52.04 \pm 11.62$ & $51.37 \pm 12.01$ & $48.98 \pm 12.20$ & $52.82 \pm 11.73$ & $52.34 \pm 12.30$ & $49.73 \pm 12.54$ & $<0.001$ \\
\hline $30-44$ & $5,007(34.4)$ & $901(30.4)$ & $791(33.9)$ & $1,144(41.5)$ & $614(28.5)$ & $543(30.8)$ & $1,014(39.3)$ & $<0.001$ \\
\hline $45-59$ & $5,437(37.4)$ & $1,179(39.8)$ & $860(36.9)$ & $994(36.0)$ & $849(39.4)$ & $635(36.0)$ & $920(35.7)$ & \\
\hline $60-74$ & 4,107 (28.2) & $884(29.8)$ & $681(29.2)$ & $619(22.5)$ & $693(32.1)$ & $584(33.2)$ & $646(25.0)$ & \\
\hline \multicolumn{9}{|l|}{ Sex } \\
\hline Male & $6,323(43.5)$ & $1,298(43.8)$ & $1,048(44.9)$ & $1,378(50.0)$ & $834(38.7)$ & $666(27.8)$ & $1,099(42.6)$ & $<0.001$ \\
\hline Female & $8,228(56.5)$ & $1,666(56.2)$ & $1,284(55.1)$ & $1,379(50.0)$ & $1,322(61.3)$ & $1,096(62.2)$ & $1,481(57.4)$ & \\
\hline Body mass index $\left(\mathrm{kg} / \mathrm{m}^{2}\right)$ & $24.03 \pm 3.40$ & $23.95 \pm 3.24$ & $24.11 \pm 3.31$ & $24.21 \pm 3.41$ & $23.87 \pm 3.34$ & $23.84 \pm 3.49$ & $24.13 \pm 3.62$ & $<0.001$ \\
\hline$<18.5 .0$ & $440(3.0)$ & 77 (2.6) & $66(2.8)$ & $69(2.5)$ & 70 (3.2) & $75(4.3)$ & 83 (3.2) & $<0.001$ \\
\hline $18.5 .0-24.9$ & $8,978(61.7)$ & $1,866(63.0)$ & $1,435(61.6)$ & $1,657(60.2)$ & $1,394(64.7)$ & $1,086(61.7)$ & $1,540(59.7)$ & \\
\hline$\geq 25.0$ & $5,126(35.2)$ & $1,021(34.4)$ & $830(35.6)$ & $1,028(37.3)$ & $692(32.1)$ & $600(34.1)$ & $955(37.0)$ & \\
\hline \multicolumn{9}{|l|}{ Marital status } \\
\hline Married & $13,487(92.7)$ & $2,802(94.5)$ & $2,159(92.6)$ & 2,451 (88.9) & $2,064(95.7)$ & $1,645(93.4)$ & 2,366 (91.7) & $<0.001$ \\
\hline Unmarried & $1,064(7.3)$ & $162(5.5)$ & $173(7.4)$ & $306(11.1)$ & $92(4.3)$ & $117(6.6)$ & $214(8.3)$ & \\
\hline \multicolumn{9}{|l|}{ Employment } \\
\hline Employed & $9,749(67.2)$ & $1,929(65.3)$ & $1,470(63.3)$ & $1,881(68.4)$ & $1,554(72.2)$ & $1,156(65.8)$ & $1,759(68.3)$ & $<0.001$ \\
\hline Unemployed & $4,767(32.8)$ & $1,026(34.7)$ & $853(36.7)$ & $870(31.6)$ & $598(27.8)$ & $602(34.2)$ & $818(31.7)$ & \\
\hline \multicolumn{9}{|l|}{ Household income $^{\dagger}$} \\
\hline Quartile 1 & $1,965(13.5)$ & $373(12.6)$ & $279(12.0)$ & $357(9.3)$ & $371(17.2)$ & $302(17.2)$ & $383(14.9)$ & $<0.001$ \\
\hline Quartile 2 & $3,624(25.0)$ & $783(26.5)$ & $567(24.4)$ & $518(18.8)$ & $663(30.8)$ & $499(28.3)$ & $594(23.1)$ & \\
\hline Quartile 3 & 4,339 (29.9) & $927(31.4)$ & $711(30.6)$ & $823(29.9)$ & $639(29.7)$ & $501(28.5)$ & $738(28.7)$ & \\
\hline Quartile 4 & $4,589(31.6)$ & $868(29.4)$ & $769(33.1)$ & $1,154(41.9)$ & $481(22.3)$ & $458(26.0)$ & 859 (33.4) & \\
\hline \multicolumn{9}{|l|}{ Smoking } \\
\hline Smoker & 2,833 (19.5) & 540 (18.2) & 409 (17.5) & $540(19.6)$ & $422(19.6)$ & $345(19.6)$ & 577 (22.4) & $<0.001$ \\
\hline Non-smoker & $11,718(80.5)$ & $2,424(81.8)$ & $1,923(82.5)$ & $2,217(80.4)$ & $1,734(80.4)$ & $1,417(80.4)$ & $2,003(77.6)$ & \\
\hline Sedentary time & $7.49 \pm 3.51$ & $3.88 \pm 1.10$ & $7.03 \pm 0.87$ & $11.19 \pm 1.92$ & $3.78 \pm 1.16$ & $7.08 \pm 1.16$ & $11.48 \pm 2.09$ & $<0.001$ \\
\hline \multicolumn{9}{|l|}{ Alcohol use } \\
\hline Drinker & $8,172(56.2)$ & $1,690(57.0)$ & $1,324(56.8)$ & $1,682(61.0)$ & $1,133(52.5)$ & $901(51.1)$ & $1,442(55.9)$ & $<0.001$ \\
\hline Non-drinker & $6,379(43.8)$ & $1,274(43.0)$ & $1,008(43.2)$ & $1,075(39.0)$ & $1,023(47.5)$ & $861(48.9)$ & $1,138(44.1)$ & \\
\hline \multicolumn{9}{|c|}{ Physical activity (METs·min/wk) } \\
\hline $\operatorname{Low}(<600)$ & $6,498(44.7)$ & 0 & 0 & 0 & $2,156(100.0)$ & $1,762(100.0)$ & $2,580(100.0)$ & $<0.001$ \\
\hline Moderate $(600-<3,000)$ & 6,328 (43.5) & $2,115(71.4)$ & $1,889(81.0)$ & 2,324 (84.3) & 0 & 0 & 0 & \\
\hline High $(\geq 3,000)$ & $1,725(11.8)$ & $849(28.6)$ & $443(19.0)$ & $433(15.7)$ & 0 & 0 & 0 & \\
\hline \multicolumn{9}{|l|}{ Comorbidities $^{\ddagger}$} \\
\hline Yes & 4,061 (27.9) & 787 (26.5) & $698(29.9)$ & 702 (25.5) & $634(29.4)$ & 549 (31.2) & $691(26.8)$ & $<0.001$ \\
\hline No & $10,490(72.1)$ & $2,177(73.5)$ & $1,634(70.1)$ & $2,055(74.5)$ & 1,522 (70.6) & $1,213(68.8)$ & 1,889 (73.2) & \\
\hline \multicolumn{9}{|l|}{ Family history of $C V D^{\S}$} \\
\hline Yes & 2,878 (19.8) & $601(20.3)$ & $484(20.8)$ & $555(20.1)$ & $388(18.0)$ & 340 (19.3) & $510(19.8)$ & 0.248 \\
\hline No & $11,673(80.2)$ & $2,363(79.7)$ & $1,848(79.3)$ & 2,202 (79.9) & $1,768(82.0)$ & $1,422(80.7)$ & 2,070 (80.2) & \\
\hline 10-Year CVD risk & $9.58 \pm 10.41$ & $9.65 \pm 10.02$ & $9.62 \pm 10.41$ & $8.85 \pm 9.98$ & $10.08 \pm 10.42$ & $10.00 \pm 10.56$ & $9.54 \pm 11.09$ & $<0.001$ \\
\hline$<10 \%$ & $9,728(66.8)$ & $1,950(65.8)$ & $1,566(67.1)$ & $1,923(69.8)$ & $1,384(64.2)$ & $1,145(65.0)$ & $1,760(68.2)$ & $<0.001$ \\
\hline$\geq 10 \%,<20 \%$ & 2,936 (20.2) & $635(21.4)$ & 445 (19.1) & $533(19.3)$ & 478 (22.2) & $375(21.3)$ & 470 (18.2) & \\
\hline$>20 \%$ & $1,887(13.0)$ & $379(12.8)$ & $321(13.8)$ & 301 (10.9) & 294 (13.6) & $242(13.7)$ & $350(13.6)$ & \\
\hline
\end{tabular}

Values are presented as mean \pm standard error or number (\%). The sum of each subgroup is not the same because of missing data. Statistically significant results are marked in bold.

MET, metabolic equivalent of task; CVD, cardiovascular disease.

${ }^{*}$ One-way analyses of variance for continuous variables and chi-square tests for categorical variables. ${ }^{\dagger}$ Quartiles were generated using the monthly average household

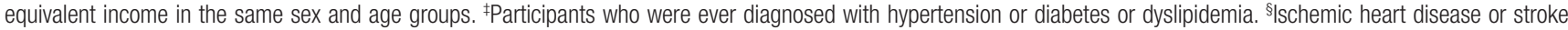
history in parents and siblings. 
level (continuous, mg/dL), total cholesterol level (continuous, $\mathrm{mg} / \mathrm{dL}$ ), presence of diabetes mellitus (categorical, yes or no), whether or not hypertension is currently treated, and current smoking status (categorical, current smoker or current non-smoker). ${ }^{19)}$

The 10-year CVD risk was categorized as low- $(<10 \%)$, intermediate$(\geq 10 \%,<20 \%)$, and high- $(>20 \%)$ risk. For the analysis, the intermediate and high risk groups were integrated and compared with the low risk group. CVD outcomes included coronary death, myocardial infarction, coronary insufficiency, angina, ischemic stroke, hemorrhagic stroke, transient ischemic attack, peripheral artery disease, and heart failure. ${ }^{10)}$ Initially, the Framingham risk score was developed to assess the risk of only coronary heart disease; however, in 2008, it was updated to include the above-mentioned conditions and has been used to predict the 10- and 30-year CVD risk of an individual.

\section{3) Definition of variables}

The following sociodemographic characteristics were considered possible confounders: age (continuous, years), sex (categorical, male or female), body mass index (BMI; continuous, $\mathrm{kg} / \mathrm{m}^{2}$ ), marital status (categorical, married or unmarried), employment (categorical, employed or unemployed), household income (categorical, 1st, 2nd, 3rd, or 4th quartile), alcohol use (categorical, drinker or non-drinker), comorbidities (categorical, yes or no), and family history of CVD (categorical, yes or no).

Blood tests and blood pressure measurements were performed. Blood test was performed after fasting for at least 8 hours from dinner before the day of the test. Blood pressure was measured 3 times every 5 minutes, and the average of the second and third blood pressure measurements was used.

BMI was calculated by dividing weight $(\mathrm{kg})$ by height squared $\left(\mathrm{m}^{2}\right)$. For the evaluation of employment status, seven occupational groups were assessed, namely, managers, office workers, service and sales workers, agricultural and fishery workers, technicians, simple labor workers, and unemployed participants (housewives and students were classified as unemployed). Household income represents the monthly average income per household and was categorized into quartiles. Participants consuming even a few cigarettes or a little alcohol were classified as current smokers or drinkers, respectively. Comorbidities were defined as a morbid state of hypertension, diabetes mellitus, or dyslipidemia. Family history of CVD included ischemic heart disease and cerebral infarction in the father, mother, or siblings.

\section{4) Statistical analysis}

The complex sample analysis was conducted for weighting assessment of the KNHANES data. To compare sociodemographic characteristics by sedentary lifestyle groups, we conducted one-way analyses of variance for continuous variables and chi-square tests for categorical variables. The results are presented as mean \pm standard error or number.

To predict the 10-year risk of CVD, the Framingham Heart Study 10year CVD risk calculator was used. To calculate the odds ratio (OR) for intermediate to high 10-year CVD risk, adjusted logistic regression analyses were performed, taking into consideration age, sex, BMI, marital status, employment, household income, alcohol use, family history of CVD, and comorbidity (history of hypertension, diabetes, and dyslipidemia). $\mathrm{P}<0.05$ was considered statistically significant. Data were analyzed using Stata MP ver. 15.0 for Windows (Stata Corp., College Station, TX, USA).

\section{RESULTS}

\section{Baseline Characteristics of Study Participants}

Table 1 shows characteristics of the participants in this study. Participants were divided into six sedentary lifestyle groups according their physical activity and sedentary time. This study included a total of 14,551 participants (6,323 men and 8,228 women), with 8,053 in the moderate/high physical activity group and 6,498 in the low physical activity group. The average age of participants was $51.10 \pm 12.14$ years. In both the moderate/high and low physical activity groups, the average age of the $<6 \mathrm{~h} / \mathrm{d}$ sedentary time group was 3 years higher than that of the $\geq 9 \mathrm{~h} / \mathrm{d}$ sedentary time group (moderate/high, 52.04 \pm 11.62 years versus $48.98 \pm 12.20$ years; low, $52.82 \pm 11.73$ years versus $49.73 \pm 12.54$ years; $\mathrm{P}<0.001)$. The proportion of women was relatively high in the low physical activity group (groups 4-6). The average BMI was $24.03 \mathrm{~kg} / \mathrm{m}^{2}$. The mean sedentary time of participants was $7.49 \mathrm{~h} /$ d. The average estimated 10 -year CVD risk was $9.58 \%$, and the risk was $\geq 10 \%$ in $33.2 \%$ of the total participants. The calculated probability of intermediate to high risk ( 10 -year risk $\geq 10 \%$ ) in each of the six groups was $34.2 \%$ (group 1), 32.9\% (group 2), 30.2\% (group 3), 35.8\% (group 4), $35.0 \%$ (group 5), and 31.8\% (group 6) (Table 1).

\section{Joint Associations of Sedentary Time and Physical Activity with the 10-Year Cardiovascular Disease Risk}

Adjusted ORs for intermediate to high 10-year CVD risk (10-year risk $\geq 10 \%$ ) are presented in Table 2. Compared with group 1 (reference group), which is the moderate/high physical activity group and has a sedentary time of $<6 \mathrm{~h} / \mathrm{d}$, after adjusting for age and sex (model 1), the OR (95\% confidence interval) was 1.001 (0.810-1.238) for group 2, 1.025 (0.843-1.247) for group 3, 1.195 (0.952-1.501) for group 4, 1.277 (1.018-1.602) for group 5, and 1.372 (1.110-1.698) for group 6. There was no significant association between sedentary time and increased 10-year CVD risk in the moderate/high physical activity groups (groups $1-3)$. In the low physical activity groups, only groups $5(\mathrm{P}<0.05)$ and $6(\mathrm{P}<0.01)$ showed statistically significant results (Table 2$)$.

After adjustments for age, sex, BMI, marital status, employment, household income, alcohol use, family history of CVD, and comorbidity, there was no significant association between sedentary time and increased 10-year CVD risk within the moderate/high physical activity groups (groups 1-3). In the low physical activity groups, the OR was $1.170(0.918-1.491)$ for group $4,1.225$ (0.964-1.557) for group 5, and 1.293 (1.035-1.615) for group 6. Among participants in the low physical activity group, the OR was the highest in the group with sedentary time 


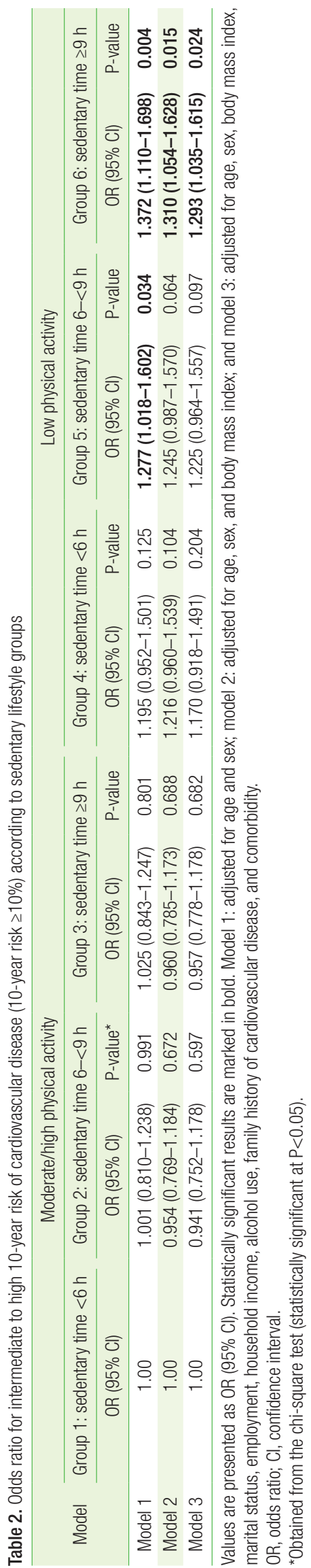

$>9 \mathrm{~h} / \mathrm{d}$ (group 6, $\mathrm{P}<0.05$ ) (Table 2, Figure 1).

In models 1-3, a sedentary time of $>9 \mathrm{~h} / \mathrm{d}$ was associated with increased 10-year CVD risk (10-year risk $\geq 10 \%$ ) in the low physical activity groups; however, low sedentary time $(<6 \mathrm{~h} / \mathrm{d})$ was not associated with increased 10-year CVD risk in the low physical activity groups.

\section{DISCUSSION}

In this cross-sectional study, low physical activity and high sedentary time were positively associated with increased 10-year CVD risk (10year risk $\geq 10 \%$ ). Furthermore, especially in the low physical activity groups, if sedentary time was $<6 \mathrm{~h} / \mathrm{d}$, there was no significant association with increased 10-year CVD risk in Korean adults, calculated using the Framingham Heart Study 10-year CVD risk calculator.

Previously, several studies have suggested that the higher the sedentary time, the higher the CVD risk. ${ }^{2,20-24)}$ Furthermore, recent studies have shown that the relationship between prolonged sedentary time and increased CVD risk is irrelevant to the physical activity level. ${ }^{2,5-9)}$ On the other hand, several studies have shown that the association between prolonged sedentary time and increased CVD mortality may become attenuated as the physical activity level increases. ${ }^{25)}$

Based on the existing WHO and Korea Health and Welfare Ministry standards, the recommended standard for physical activity in adults is moderate-intensity exercise for $>150$ minutes per week or $>1$ hour 15 minutes per week for vigorous-intensity exercise. When 4.0 METs are applied to moderate-intensity exercise and 8.0 METs are applied to vigorous-intensity exercise, the recommended amount of exercise is $600 \mathrm{METs} \cdot \mathrm{min} / \mathrm{wk}^{26)}$ It can be expected that the probability of a significant increase of 10-year CVD risk would not be higher even if the sedentary time increases, when physical activity is maintained at $>600$ METs.min/wk.

Additionally, keeping the sedentary time $<6 \mathrm{~h} / \mathrm{d}$ was not associated

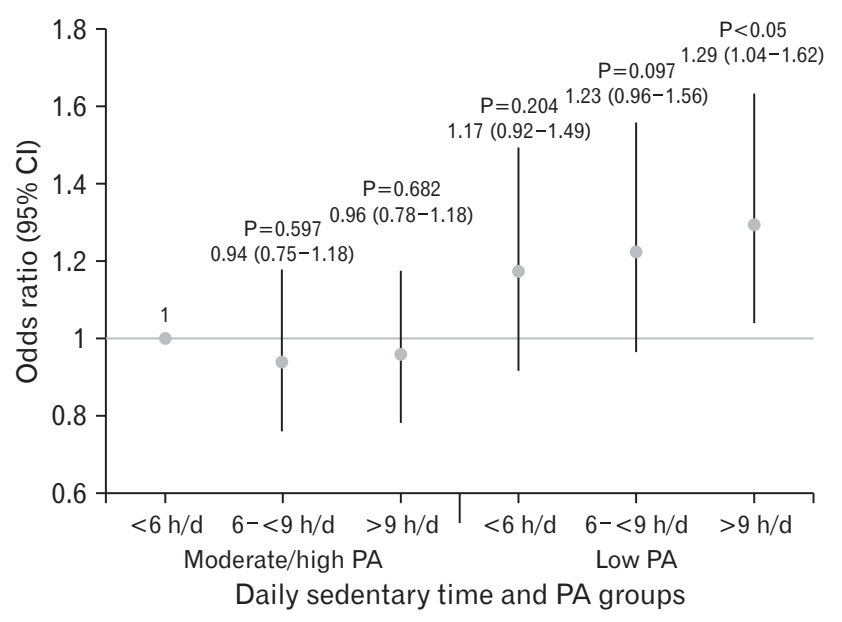

Figure 1. Joint associations of sedentary time, PA groups, and intermediate to high 10 -year cardiovascular disease risk (10-year risk $\geq 10 \%$ ). Odds ratio of the low PA group with $>9 \mathrm{~h} / \mathrm{d}$ sedentary time is $1.29 \pm 0.15$, which is a statistically significant result $(\mathrm{P}<0.05)$. $\mathrm{PA}$, physical activity; $\mathrm{Cl}$, confidence interval. 
with an increased 10-year CVD risk of $>10 \%$, even if physical activity was $<600 \mathrm{METs} \cdot \mathrm{min} / \mathrm{wk}$. On the basis of these results, it would be beneficial to keep the sedentary time $<6 \mathrm{~h} / \mathrm{d}$ if physical activity is below the recommended amount.

The present study has many strengths. To the best of our knowledge, this is the first study to evaluate the relationship between sedentary time, physical activity, and 10-year CVD risk using a large representative sample of Korean adults. In addition, we adjusted for various sociodemographic and CVD-related factors. Further, whereas previous studies included individuals with preexisting conditions, we excluded patients who were diagnosed with cancer, stroke, angina, and myocardial infarction.

However, there are also several limitations to this study. First, the surrogate marker for increased CVD risk outcome is based on the Framingham risk score. The Framingham risk score has been known to overestimate the risk in the Asian-Pacific population. ${ }^{27,28)}$ Although the tool suggested by the American College of Cardiology (ACC)/ American Heart Association (AHA), the Pooled Cohort risk assessment equation, shows better predictability, this is also susceptible to overestimation when applied to the Asian population. ${ }^{29)}$ Meanwhile, the Korean risk prediction model, which was developed based on the ACC/AHA prediction model, is considered to show more predictability for the Korean population; ${ }^{30)}$ however, there are not enough tools available to clinicians and patients. The Framingham study-related model, which was also used in this study, has the advantage of having a high clinical utilization. However, its clinical use has been greatly reduced owing to the development of a new predictive model and numerous limitations to consider at present. Second, this study could not identify the minimum cutoff value of sedentary time to avoid increasing the 10-year CVD risk in each physical activity group, as sedentary time in this study was classified using an arbitrarily defined criterion. The third limitation is that this was a cross-sectional study. Thus, it is only possible to present a link to the results, as we could not intervene in the data collection process. There were also limitations in inferring causal relationships between data. The fourth limitation is that this study was based on self-reported results collected through surveys of sedentary time and physical activity. Therefore, there is a possibility of participant bias, resulting in a lack of objectivity and standardization and possibly reducing the reliability owing to recall errors.

In summary, our analysis of sedentary time, physical activity, and increased 10-year CVD risk found that in low physical activity groups, low sedentary time $(<6 \mathrm{~h} / \mathrm{d})$ was not associated with increased 10-year CVD risk. From this point of view, reduction of sedentary time can be an important strategy for preventing the increase of CVD risk in populations with low physical activity, especially in those with less than the recommended amount of exercise or those who do not exercise sufficiently because of occupational characteristics. Thus, further longitudinal cohort studies are required and providing education on the importance of reducing sedentary time is needed.

\section{CONFLICT OF INTEREST}

No potential conflict of interest relevant to this article was reported.

\section{ORCID}

Yena Lee: https://orcid.org/0000-0002-6356-3121

Joung Sik Son: https://orcid.org/0000-0003-2460-3378

Yoon Hee Eum: https://orcid.org/0000-0002-8280-9529

Ok Lim Kang: https://orcid.org/0000-0002-2802-7876

\section{REFERENCES}

1. World Health Organization. Physical activity [Internet]. Geneva: World Health Organization; 2018 [cited 2019 Sep 23]. Available from: https:// www.who.int/news-room/fact-sheets/detail/physical-activity.

2. Biswas A, Oh PI, Faulkner GE, Bajaj RR, Silver MA, Mitchell MS, et al. Sedentary time and its association with risk for disease incidence, mortality, and hospitalization in adults: a systematic review and metaanalysis. Ann Intern Med 2015;162:123-32.

3. Sedentary Behavior Research Network. SBRN: terminology consensus project [Internet]. Ottawa (ON): Sedentary Behavior Research Network; 2017 [cited 2019 Sep 23]. Available from: https://www.sedentarybehaviour. org/sbrn-terminology-consensus-project/.

4. Statistics Korea. Cause of death statistics, 2017 [Internet]. Daejeon: Statistics Korea; 2018 [cited 2019 Sep 23]. Available from: http://kostat. go.kr/portal/korea/kor_nw/1/6/2/index.board?bmode=read\&aSeq= 370710 .

5. Chomistek AK, Manson JE, Stefanick ML, Lu B, Sands-Lincoln M, Going SB, et al. Relationship of sedentary behavior and physical activity to incident cardiovascular disease: results from the Women's Health Initiative. J Am Coll Cardiol 2013;61:2346-54.

6. Seguin R, Buchner DM, Liu J, Allison M, Manini T, Wang CY, et al. Sedentary behavior and mortality in older women: the Women's Health Initiative. Am J Prev Med 2014;46:122-35.

7. Stamatakis E, Hamer M, Dunstan DW. Screen-based entertainment time, all-cause mortality, and cardiovascular events: populationbased study with ongoing mortality and hospital events follow-up. J Am Coll Cardiol 2011;57:292-9.

8. Wijndaele K, Brage S, Besson H, Khaw KT, Sharp SJ, Luben R, et al. Television viewing time independently predicts all-cause and cardiovascular mortality: the EPIC Norfolk study. Int J Epidemiol 2011;40:150-9.

9. Katzmarzyk PT, Church TS, Craig CL, Bouchard C. Sitting time and mortality from all causes, cardiovascular disease, and cancer. Med Sci Sports Exerc 2009;41:998-1005.

10. D'Agostino RB Sr, Vasan RS, Pencina MJ, Wolf PA, Cobain M, Massaro $\mathrm{JM}$, et al. General cardiovascular risk profile for use in primary care: the Framingham Heart Study. Circulation 2008;117:743-53.

11. World Health Organization. WHO STEPS surveillance manual: the WHO STEPwise approach to chronic disease risk factor surveillance. Geneva: World Health Organization; 2005.

12. Armstrong T, Bull F. Development of the World Health Organization Global Physical Activity Questionnaire (GPAQ). J Public Health 
2006;14:66-70.

13. Jeon Y. Development of the Korean version of global physical activity questionnaire and assessment of reliability and validity. Cheongju: Korea Centers for Disease Control and Prevention; 2013.

14. Stamatakis E, Gale J, Bauman A, Ekelund U, Hamer M, Ding D. Sitting time, physical activity, and risk of mortality in adults. J Am Coll Cardiol 2019;73:2062-72.

15. Pandey A, Salahuddin U, Garg S, Ayers C, Kulinski J, Anand V, et al. Continuous dose-response association between sedentary time and risk for cardiovascular disease: a meta-analysis. JAMA Cardiol 2016;1: 575-83.

16. International Physical Activity Questionnaire. Guidelines for data processing and analysis of the International Physical Activity Questionnaire (IPAQ) [Internet]. [place unknown]: International Physical Activity Questionnaire; 2005 [cited 2019 Sep 23]. Available from: https:// sites.google.com/site/theipaq/scoring-protocol.

17. World Health Organization. Global Physical Activity Questionnaire (GPAQ) analysis guide [Internet]. Geneva: World Health Organization [cited 2019 Sep 23]. Available from: https://www.who.int/ncds/surveillance/steps/resources/GPAQ_Analysis_Guide.pdf.

18. World Health Organization. Physical-activity-recommendations [Internet]. Geneva: World Health Organization [cited 2019 Sep 23]. Available from: https://www.who.int/dietphysicalactivity/leaflet-physicalactivity-recommendations.pdf?ua=1.

19. Framingham Heart Study. Cardiovascular disease (10-year risk) [Internet]. Framingham (MA): Framingham Heart Study [cited 2019 Sep 23]. Available from: https://www.framinghamheartstudy.org/fhs-riskfunctions/cardiovascular-disease-10-year-risk/.

20. Borodulin K, Karki A, Laatikainen T, Peltonen M, Luoto R. Daily sedentary time and risk of cardiovascular disease: the national FINRISK 2002 study. J Phys Act Health 2015;12:904-8.

21. Bjork Petersen C, Bauman A, Gronbaek M, Wulff Helge J, Thygesen LC, Tolstrup JS. Total sitting time and risk of myocardial infarction, coronary heart disease and all-cause mortality in a prospective cohort of Danish adults. Int J Behav Nutr Phys Act 2014;11:13.

22. Chomistek AK, Manson JE, Stefanick ML, Lu B, Sands-Lincoln M, Go- ing SB, et al. Relationship of sedentary behavior and physical activity to incident cardiovascular disease: results from the Women's Health Initiative. J Am Coll Cardiol 2013;61:2346-54.

23. Grontved A, Hu FB. Television viewing and risk of type 2 diabetes, cardiovascular disease, and all-cause mortality: a meta-analysis. JAMA 2011;305:2448-55.

24. Herber-Gast GC, Jackson CA, Mishra GD, Brown WJ. Self-reported sitting time is not associated with incidence of cardiovascular disease in a population-based cohort of mid-aged women. Int J Behav Nutr Phys Act 2013;10:55.

25. Ekelund U, Steene-Johannessen J, Brown WJ, Fagerland MW, Owen N, Powell KE, et al. Does physical activity attenuate, or even eliminate, the detrimental association of sitting time with mortality?: a harmonised meta-analysis of data from more than 1 million men and women. Lancet 2016;388:1302-10.

26. World Health Organization. Global strategy on diet, physical activity and health [Internet]. Geneva: World Health Organization; 2004 [cited 2019 Sep 23]. Available from: https://www.who.int/dietphysicalactivity/factsheet_adults/en/.

27. Liu J, Hong Y, D’Agostino RB Sr, Wu Z, Wang W, Sun J, et al. Predictive value for the Chinese population of the Framingham CHD risk assessment tool compared with the Chinese Multi-Provincial Cohort Study. JAMA 2004;291:2591-9.

28. Jee SH, Jang Y, Oh DJ, Oh BH, Lee SH, Park SW, et al. A coronary heart disease prediction model: the Korean Heart Study. BMJ Open 2014;4: $\mathrm{e} 005025$.

29. Goff DC Jr, Lloyd-Jones DM, Bennett G, Coady S, D'Agostino RB Sr, Gibbons R, et al. 2013 ACC/AHA guideline on the assessment of cardiovascular risk: a report of the American College of Cardiology/ American Heart Association Task Force on Practice Guidelines. J Am Coll Cardiol 2014;63(25 Pt B):2935-59.

30. Jung KJ, Jang Y, Oh DJ, Oh BH, Lee SH, Park SW, et al. The ACC/AHA 2013 Pooled Cohort equations compared to a Korean Risk Prediction Model for atherosclerotic cardiovascular disease. Atherosclerosis 2015;242:367-75. 